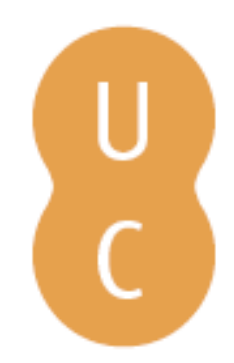

\title{
pompalina
}

\section{Espaços da morte na historiografia de Tácito}

Autor(es): $\quad$ Pimentel, Maria Cristina

Publicado por: Associação Portuguesa de Estudos Clássicos; Imprensa da

URL

persistente: URI:http://hdl.handle.net/10316.2/31794

DOI: DOI:http://dx.doi.org/10.14195/978-989-721-069-3_31

Accessed : $\quad$ 26-Apr-2023 15:26:35

A navegação consulta e descarregamento dos títulos inseridos nas Bibliotecas Digitais UC Digitalis, UC Pombalina e UC Impactum, pressupõem a aceitação plena e sem reservas dos Termos e Condições de Uso destas Bibliotecas Digitais, disponíveis em https://digitalis.uc.pt/pt-pt/termos.

Conforme exposto nos referidos Termos e Condições de Uso, o descarregamento de títulos de acesso restrito requer uma licença válida de autorização devendo o utilizador aceder ao(s) documento(s) a partir de um endereço de IP da instituição detentora da supramencionada licença.

Ao utilizador é apenas permitido o descarregamento para uso pessoal, pelo que o emprego do(s) título(s) descarregado(s) para outro fim, designadamente comercial, carece de autorização do respetivo autor ou editor da obra.

Na medida em que todas as obras da UC Digitalis se encontram protegidas pelo Código do Direito de Autor e Direitos Conexos e demais legislação aplicável, toda a cópia, parcial ou total, deste documento, nos casos em que é legalmente admitida, deverá conter ou fazer-se acompanhar por este aviso.

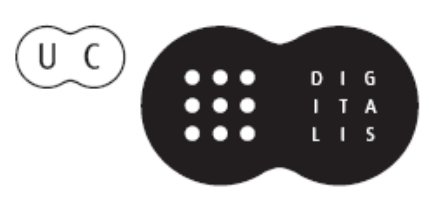




\section{Espaços e Paisagens}

\section{Antiguidade Clássica e Heranças Contemporâneas}

Vol. I Línguas e Literaturas. Grécia e Roma

Francisco de Oliveira, Cláudia Teixeira, Paula Barata Dias (coords.)

IMPRENSA DA UNIVERSIDADE DE COIMBRA 


\title{
ESPAÇOS DA MORTE NA HISTORIOGRAFIA DE TÁCITO
}

\author{
Maria Cristina Pimentel \\ Faculdade de Letras da Universidade de Lisboa \\ c.pimentel@fl.ul.pt
}

\begin{abstract}
Résumé
Tacite est, en général, peu prolixe dans la description des espaces physiques où se déroulent les événements évoqués dans son histoire. Il est donc très significatif d'observer les passages où une spéciale attention est accordée aux espaces servant de décor à la tragédie de ceux qui tombent en disgrâce. Lévocation de ces espaces souligne le réalisme et le pathétique de la scène et conduit le lecteur à une réflexion sur les mécanismes de la tyrannie et, en dernier ressort, sur la condition humaine. Une analyse centrée sur les six premiers livres des Annales, met en évidence le fait que les crimes de Tibère semblent se concentrer dans un nombre restreint de lieux (îles, prisons, rues et places de Rome, la curie, l'intérieur des maisons), auxquels Tacite attribue non seulement une valeur descriptive mais aussi une dimension symbolique que le lecteur est à même de déchiffrer.
\end{abstract}

Palavras-chave: Annales, espaços da morte, historiografia trágica, Tácito, Tibério, tirania.

Um homem está na margem de uma ilha e fixa os olhos na imensidão do mar. Ele sabe que hão-de vir para tirar-lhe a vida. Está há catorze anos exilado, mas talvez tenha sabido ou pressinta que a morte de Augusto dará enfim a Tibério o poder de soltar a ira e saciar o seu rancor.

O homem que Tácito assim nos apresenta é Semprónio Graco, implicado em processo por adultério com a filha de Augusto e exilado numa ilha junto à costa da Africa. Ele é uma das primeiras vítimas de Tibério, uma entre muitas de uma longa lista de assassínios, execuções e suicídios com que Tácito leva o leitor a reflectir sobre os mecanismos da tirania e, em última instância, sobre a própria condição humana.

Graco não é, nem Tácito quer que pensemos que era, alguém cuja conduta e carácter merecessem louvor. Bem pelo contrário: o historiador não deixa de registar a indignidade que lhe valeu o exílio. Mas o que pretende ao mostrá-lo, só, longe de tudo e de todos, à beira do mar e à espera do fim, nibil laetum opperientem (Ann. 1.53.5), é dá-lo como exemplo de alguém cuja atitude perante a morte como que redimiu a vida pautada pela dissolução. E é também escrever mais um apontamento que, somado a muitos outros dos seis primeiros livros dos Annales, se traduzirá no balanço funesto de um principado marcado 
pelo terror e pela arbitrariedade, tema que atravessa toda a obra, sustentando a reflexão sobre o regime político instituído por Augusto.

E a imagem que guardamos - a que Tácito sem dúvida quis que guardássemos - é essa: um homem está sozinho e sem defesa perante a morte. Sobre ele abatese a força cega da prepotência imperial. Numa ilha, como se esse espaço fechado, essas margens que o cercam, simbolizassem a impossibilidade de escapar à violência e à fortuna adversa. Graco, porém, não se deixa vergar pelo medo, nem abdica de ser homem e olhar a morte com serenidade e coragem, com a constantia desejada pelos estóicos. Não é como bicho acossado ou conduzido ao abate que ele quer sair da vida. Por isso, aos soldados que vêm para o matar e que sem dúvida viu aproximarem-se da fímbria da ilha onde Tácito o foca, pede apenas um breue tempus para escrever à mulher as derradeiras vontades. Depois, sem vacilar, ceruicem... percussoribus obtulit.

Graco não é a primeira vítima de Tibério após a sua ascensão ao poder. Tácito evocara já o primum facinus (1.6.1) desse principado, o assassínio de Agripa Póstumo, último neto de Augusto. Exilado na ilha de Planásia, também ele está sem armas e indefeso quando o tribuno que o vigia, em cumprimento de ordens vindas de Roma, o surpreende e mata. Agripa, porém, resistiu à morte, deu luta, o que é coerente com a informação anterior de que era trux, estupidamente orgulhoso da sua força física, e desprovido de qualquer cultura $(1.3 .4 ; 4.3)$. Isso não impede, todavia, que no momento da morte Tácito o fixe numa atitude não isenta de dignidade, recusando-se a morrer sem ao menos opor a resistência de quem nada tem de que se acusar.

Ora, se observarmos que o fim de Graco é evocado no mesmo capítulo em que se regista a morte de Júlia, outrora sua amante e filha de Augusto, repudiada mulher de Tibério e mãe de Agripa, veremos que a associação entre estas três figuras não pode ser involuntária por parte do historiador e sugere muito mais do que uma leitura imediata que a justifique pelos laços afectivos e de sangue que os unem. Tácito deixa-nos entrever, associando-os na morte, a funesta coerência de Tibério ao concertar uma vingança ansiada durante anos: Agripa, último filho de Júlia e sua derradeira esperança, foi o primeiro a ser morto, por medo de que constituísse ameaça política. Depois veio a vingança contra a mulher que atentou contra a sua honra, que o pôs a ridículo com sucessivos e públicos adultérios. Para ela reservou uma morte lenta, à míngua de tudo, convencido de que passaria desapercebido o seu desaparecimento após tantos anos longe de Roma. Na mesma altura, faz executar Graco, que o afrontara, que incitara Júlia a desrespeitá-lo e fora um dos muitos amantes dela: por isso é como se Tibério nele quisesse aniquilar todos aqueles com quem Júlia se cobrira e o cobrira a ele de opróbrio.

Deste modo, Tácito mostra-nos Tibério como alguém que, guardando dentro de si um ódio rancoroso que só se saciava com sangue, há muitos anos esperava o momento em que pudesse acertar as contas com os que o haviam insultado, em que tivesse as mãos livres para afastar do caminho todos os que lhe pareciam representar uma ameaça ao seu poder.

A unir as três vítimas está também um espaço fechado, de cerco: Júlia morre 
no oppidum de Rhegium, guardada à vista; Agripa e Graco cada um em sua ilha, aquele morto pela guarda destacada para o vigiar, este por soldados enviados para o assassinarem. O fim destas personagens, separadas no espaço mas unidas no ano da morte e na história comum, torna-se assim o primeiro andamento de uma composição de tons dissonantes que incomoda a alma de quem lê e nos põe de imediato na expectativa de uma sequência atroz de massacres no principado de Tibério.

A atenção aos espaços em que se desenrola a tragédia daqueles que caem em desgraça, como forma de dar mais realismo ou sublinhar o patético de um quadro, é também expressiva no caso de Libão Druso. Acusado de conspirar contra Tibério, Tácito entende que o processo de que foi alvo merece um relato especialmente cuidado, já que foi o primeiro de muitos que durante tantos anos minaram o Estado. Saímos, pois, de uma esfera pessoal, a dos afectos e desafectos de Tibério, para passarmos a um mal mais persistente e devastador: aquele que atingirá os melhores de Roma, quase sempre inocentes dos crimes de que os acusam.

Libão tem contra si quem lhe é próximo. O primeiro a provocar-lhe a ruína é um amigo íntimo, que aproveita a sua juventude, inexperiência e irreflexão para o incentivar à consulta dos astrólogos e o levar a vangloriar-se da sua estirpe e da justeza da pretensão a um destino mais alto. Apanhado numa cilada de que não conseguirá sair, Druso apercebe-se da desgraça iminente e tenta encontrar quem, no senado onde será julgado, o defenda. Tácito retratathe a aflição (2.29), indo de casa em casa (circumire domos) a suplicar aos que lhe eram próximos que alguém aceite apoiá-lo. Mas, desse movimento que se adivinha em crescente desespero, apenas resulta a extrema fraqueza que o leva a, no dia do processo, ter de ser transportado de liteira até às portas da cúria, derrotado de medo e de inquietação. À sua volta fizera-se um deserto, pois todos the tinham negado ajuda, invocando diversos pretextos que, segundo Tácito, tinham no entanto a mesma causa: o terror (eadem formidine) perante o risco de também eles serem acusados. $\mathrm{O}$ historiador não censura os que assim agiram. Dir-se-á que os compreende. Mas as muitas vezes em que acusa os grandes de Roma, particularmente os senadores, de segnitia, de patientia seruilis, de falta de solidariedade entre si, de cobardia vergonhosa que a nada conduz pois os torna cada vez mais desprotegidos perante a violência do princeps, sem dúvida estão na mente do leitor. $\mathrm{E}$ Druso, com toda a inconsciência da sua juventude, a sua bybris que o vai perder, torna-se, no momento da queda, uma vítima que, aos nossos olhos, desperta tão-só comiseração e simpatia.

Tácito detém-se então nos últimos momentos de Druso. Ouvindo as acusações e percebendo que nada o poderia salvar, ele pede que a sessão do senado seja suspensa até ao dia seguinte. Da cúria, Tácito conduz-nos até casa de Druso, onde o último acto desta tragédia terá lugar. Toda a casa está cercada e invadida por soldados, que ostensiva e ruidosamente se manifestam no vestíbulo para que os ouçam e vejam. A manobra de intimidação é evidente, tal como é claro, pelo verbo que Tácito escolhe e usa na voz passiva (2.31.1: cingebatur), que Druso está no centro de um círculo que se aperta em torno 
dele. Pensara que um festim lhe adoçaria as derradeiras horas, em vez disso é tormento o que sente, a ponto de querer pôr termo à vida sem mais esperar. Implora aos escravos que o matem, mas todos recusam e o deixam, tomados pela força centrífuga que é o medo: uma vez mais, Druso é abandonado por todos. $\mathrm{Na}$ aflição com que dele fogem, tomba a candeia colocada sobre a mesa e a sala mergulha na escuridão, numas trevas funestas que prenunciam as da morte. É nessa noite negra, nessa sala cercada de soldados ameaçadores e vazia de mãos que o ajudem, que Druso se fere no ventre. Tácito faz-nos escutar o gemido, o som do corpo que cai pesadamente, ouvido pelos libertos que só então acorrem, num movimento contrário ao de pouco antes (refugiunt... adcurrere), logo seguidos dos soldados que, vendo-o morto, finalmente se retiram da casa, espaço privado que a sua bruteza violara. A morte de Druso é formalmente um suicídio. Mas Tácito, com o pormenor dado ao episódio, mostra que foi como um assassínio programado e executado, com fria lucidez, pelos pares de Druso e, em última instância, por Tibério.

O quadro deste processo aproxima-se, em significativos aspectos, do de Pisão, o alegado assassino de Germânico. Também aqui há dois espaços que se sucedem, correspondendo a dois momentos diferentes, mas igualmente trágicos, do episódio: a cúria, onde Pisão é julgado; a sua própria casa, onde se suicida, antecipando-se à condenação inevitável. $\mathrm{Na}$ cúria, enquanto se esmiúçam os agravos, ouve-se a populaça ameaçar que invadirá a sala se o réu não for condenado. Em torno de Pisão, como acontecera com Druso, aperta-se um duplo laço: um primeiro nó, o dos senadores reunidos para o perder; um segundo, o da multidão que aguarda, incontida e minaz. Quando a sessão é suspensa, Pisão é levado numa liteira, acompanhado pelo tribuno da guarda pretoriana. Como Libão, também ele regressa a casa sob custódia.

Em nova sessão do senado, Pisão tenta ainda defender-se, mas percebe que não tem salvação. De novo Tácito nos mostra um homem ao lado de quem ninguém ficou, abandonado até pela mulher, Plancina, inicialmente implicada com ele mas que, garantido o apoio de Lívia, se afasta do marido deixando-o à mercê da sua sorte. É essa commutatio fortunae que o historiador realça, fazendo o leitor esquecer que sobre Pisão pesa a acusação gravíssima, não de todo infundada, de ter envenenado Germânico, o amado general que quase todos queriam ver suceder a Tibério. Ora, o próprio princeps, que teria sido o mandante do crime, via-o agora Pisão num mutismo sine miseratione, sine ira, obstinatum clausumque (3.15.2), dominando e escondendo qualquer sinal de sentimento ou emoção. É isso que o decide a morrer e, assim, Tácito leva uma vez mais o leitor a atribuir a Tibério a responsabilidade dessa morte. Pisão regressa a casa: aí, sob pretexto de preparar a defesa para o dia seguinte, escreve uma carta ao princeps, cumpre os habituais preceitos de higiene e, noite dentro, depois de a mulher ter saído do quarto, mandou que trancassem a porta. Ao romper do dia, encontraram-no caído, a garganta cortada com a própria espada.

Se o processo, a parte pública deste drama, se desenrolou na cúria, é em casa, com a serenidade e a firmeza que os ritos quotidianos revelam, com o 
ânimo corajoso com que, por escrito, afirma a Tibério a sua inocência e a sua nunca quebrada lealdade para com ele, que Pisão nos surge, pela arte de Tácito, mais profundamente humano no desejo de privacidade na morte. Sozinho - como sozinho estava frente às forças que o esmagavam - no silêncio da noite e na estreiteza de um cubiculum, Pisão é mais uma figura que Tácito nos mostra na complexidade do ser humano que erra, mas nem por isso deixa de merecer a nossa admiração quando aceita a morte, não com o rosto cabisbaixo dos vencidos, mas com a cabeça erguida de quem a fita sem frémito da consciência.

$\mathrm{Na}$ sua escalada contra a família de Germânico e todos os que conservassem amizade ou lealdade para com ela, Tibério decide, no ano 28, aniquilar Tício Sabino. Tácito mostra tudo o que, neste caso, foi ignominioso: antes do mais regista o facto de a prisão e ruína de Sabino ter tido lugar no início do ano, o que, atendendo à sacralidade da época, configura um foedum principium (4.68.1). É nesse momento em que se tomam auspícios inaugurais que ele é arrastado para a prisão. A indignidade do que tem de suportar é depois realçada pela referência ao seu estrato social (inlustri equite Romano). Só então Tácito revela as causas da sua perdição: ob amicitiam Germanici; e porque não tinha desamparado a viúva, Agripina, e os filhos, que continuara a visitar e a acompanhar publicamente.

Tácito relata em analepse os pormenores da armadilha que lhe prepararam, enumerando, em jeito de denúncia, o nome dos quatro antigos pretores que, para agradarem a Sejano e, assim, poderem aspirar ao consulado, se uniram para o incriminarem. Sabino não se apercebeu do dolo, confiou em quem julgava ser sincero na sua comiseração por Agripina e os filhos, no ódio expresso por Sejano e por Tibério. O historiador desvenda, como faz em muitas outras ocasiões, uma fallax amicitia que se empenha em perder alguém de carácter impoluto. Sabino deixa-se iludir por essa species artae amicitiae (68.4) e é como que apanhado numa ratoeira.

O espaço escolhido para que ele se incrimine perante testemunhas é a própria casa de Laciar, o chefe de fila dos perseguidores, que Tácito faz questão de referir por senatores para acentuar a vileza de membros da primeira ordem do Estado. É na casa dele que os outros três se escondem, para surpreender o que Sabino disser. Mas, por receio de que um ruído ou movimento inadvertido os denuncie, não o fazem colocando-se atrás de uma porta: escondem-se antes num espaço entre o telhado e o tecto da casa (tectum inter et laquearia). Tácito, que regra geral é escasso na descrição dos espaços físicos em que decorrem os acontecimentos recordados na sua história, indica aqui com precisão o local onde eles se dissimulam. E fá-lo porque pretende denunciar a torpeza do expediente e a infâmia dos senadores, que nos faz ver como ratos no forro de uma casa, imóveis e à espreita, o ouvido colado a todas as fendas e orifícios. Laciar, entretanto, atraiu Sabino à cilada: encontrou-o in publico e depois levou-o domum et in cubiculum. A sequência é eloquente: de um local aberto, uma rua onde Sabino sem dúvida estaria de sobreaviso contra os ouvidos de todos os que passassem, Laciar leva-o para sua casa, espaço fechado onde Sabino se julgará 
seguro. Mas o leitor, a quem Tácito já desvendou o ardil vergonhoso, sobre o qual expressou juízo de valor peremptório - haud minus turpi latebra quam detestanda fraude (69.1) - o leitor sabe que Sabino, na confiada inconsciência das vítimas que não pressentem o seu destino, entra no local da sua perdição. Em casa de Laciar, é para o quarto deste que Sabino é levado. O espaço mais íntimo do suposto amigo, aquele onde julga que a confidencialidade é absoluta, é afinal o espaço mais estreito em que o nó se aperta: e ele fala, fala abundante e abertamente da sua dor e dos agravos imperiais. Julga que ninguém o ouve, mas ele, que se acautelara das ruas devassadas, não sabe que outros ouvidos esses sim, traiçoeiros - o escutam e fixam todas as palavras sobre as quais logo darão testemunho em carta ao imperador, na qual, além das acusações, expõem despudoradamente e sem pejo a fraus a que recorreram.

Tácito termina o capítulo com uma desencantada e ominosa evocação do efeito que a notícia dos meandros da maquinação teve em Roma. Em hipérbole carregada de significado, pelo que anuncia de um tempo em que não mais haveria quem se sentisse seguro, onde quer que estivesse ou com quem quer que falasse, acentua os dois sentimentos que dominaram a cidade, a inquietação e o medo, numa personificação (anxia et pauens) que dá relevo ao comportamento que a partir daí se impôs a todos: a necessidade de dissimular opiniões e sentimentos, por desconfiança mesmo dos mais próximos, e de evitar qualquer reunião ou conversa (a aliteração congressus conloquia frisa a regra absoluta em que essa atitude se transforma), por medo de quem pudesse ouvir o que se dissesse; a sinédoque aures, remetendo para os ouvidos que registaram as palavras de Sabino, traduz, ampliando, o ambiente de permanente perigo e desconfiança que os delatores criavam, como se em toda a parte só houvesse ouvidos pérfidos à escuta; do mesmo modo, a antítese notae ignotaeque, qualificativos de aures, aponta para a urgência de, para salvaguardar a vida, não se confiar em ninguém. A frase que fecha o capítulo, último membro de uma gradação ascendente que sugere a escalada do clima de terror, mostra que a necessidade de ficar de sobreaviso e de absoluta precaução se alargou inclusive aos objectos mudos e inanimados e que, por isso, todos examinavam, espiando os mais ínfimos recantos, até o tecto e as paredes das casas (tectum et parietas), expressão que estabelece um nexo directo de causalidade entre a armadilha forjada contra Sabino e a pesada nuvem de insegurança e pavor que esmagou a cidade.

Tácito, que no início do episódio nos mostrara Sabino tracto in carcerem, suspendendo depois a sequência da narrativa para nos dar a conhecer como se tramou a sua desgraça, volta no cap. 70 à ordem cronológica interrompida para fixar nele o olhar no dia da execução. A cena está carregada de dramatismo e o estilo de Tácito é deveras sublime neste passo: o condenado é arrastado para o suplício, não é, pois, uma daquelas vítimas que sofrem em silêncio a desgraça, sem ao menos reagirem denunciando a prepotência que os derruba. É isso que traduz trahebatur, forma do mesmo verbo que liga ambos os momentos da acção, passiva que no-lo mostra levado pelas ruas como ser infenso, uma corda a apertar-lhe o pescoço e as vestes a cobrirem-lhe o rosto, gritando sem cessar (clamitans), na medida em que o conseguia fazer sob os constrangimentos 
a que o sujeitavam, a denúncia das circunstâncias torpes em que o tinham incriminado e o levavam a morrer: num estertor último de quem conhece e acusa os seus verdadeiros inimigos, revela que é imolado como vítima a Sejano, sombra funesta por trás de todos os malvados, e clama contra o acto sacrílego de uma execução no início do ano.

Os gritos de Sabino pareciam, todavia, não encontrar eco em ninguém. Tácito acentua, com o quiasmo intendisset oculos... uerba acciderent $\mathrm{e} o$ assíndeto de fuga, uastitas... itinera, fora, o deserto que, pelas ruas e praças, se ia fazendo em torno dele. Todos fogem por medo, sabe-o o leitor sem que Tácito tenha de o dizer. Mas a esse movimento centrífugo que deixa o condenado a sós com os seus verdugos sucede-se um movimento centrípeto que traz de volta (regrediebantur) uns quantos dos que haviam fugido e os faz mostrarem-se de novo (ostentabantque se rursus), aterrorizados pelo próprio pavor que sentem. Observando aqueles cuja consciência lhes revela uma terrível hierarquia de medos, o medo de morrer e o medo de ser capaz de tudo para não morrer, Tácito entra no mais íntimo e secreto dos lugares, onde se pesa e decide a dignidade ou a infâmia de um ser humano. E, para mostrar que nem todos fecharam os ouvidos e a consciência às palavras derradeiras de Sabino, que nem todos se deixaram dominar pelo medo e se refugiaram na frágil segurança da indiferença à desgraça alheia, Tácito reproduz o que pensavam, a assustada indignação perante a impiedade de Tibério ao manchar aquele dia com a aplicação da pena capital, e que a comparação quomodo delubra et altaria, sic carcerem recludant (70.3) põe a nu.

Também o episódio de Consídio Próculo, acusado de maiestas (6.18), sublinha a desumanidade quase sacrílega com que Tibério atingia as suas vítimas. $\mathrm{O}$ historiador inicia o capítulo com a afirmação de que uma nova vaga de perseguições e processos se verificou nesse ano de 33, fazendo recrudescer o medo, sentimento que, por isso, orienta e determina toda a leitura do texto subsequente: processo sabiamente usado por Tácito, que só raras vezes e por pouco tempo deixa ao leitor espaço para se debruçar sobre outros acontecimentos sem que a sombra da repressão e da tirania paire sobre o relato e se materialize numa série de assassínios, execuções sumárias, suicídios e exílios, num acumular de episódios sangrentos que acabam por nos dar a sensação, sem dúvida desejada por Tácito, de que o principado de Tibério - e, depois, o de Nero - foi uma espiral de violência sem freio nem remissão.

Próculo é surpreendido por essa violência sem que nada o fizesse suspeitar do que o aguardava, sem que nada temesse quanto ao seu destino. Focando-o nullo pauore enquanto celebrava o seu aniversário, Tácito sugere ao leitor a tranquilidade que só as consciências inocentes experimentam, enquanto acentua o abuso da crueldade que desfecha o golpe num dia de festa familiar, dia de alegria em que o próprio culto aos deuses proibia os sacrifícios sangrentos. Próculo é arrancado à família, à sua casa, levado de imediato para a cúria, condenado em processo sumário e executado no instante seguinte. Toda esta pressa que o leva, num ápice, do espaço da vida e do júbilo, ao abismo da desgraça e da morte, é sublinhado pelo recorte da frase: em raptus in curiam pariterque damnatus 
interfectusque, ao homeoteleuto dos particípios e ao polissíndeto que os une vem juntar-se a carga semântica da censura que o advérbio pariter faz pesar sobre aqueles para quem a referência espacial in curiam aponta: os senadores, coniventes, na sua subserviência e por medo, com a tirania de Tibério.

Já perto do fim da vida, porém, Tibério não saciou ainda o seu ressentimento contra todos os descendentes de Germânico. Às circunstâncias da morte de um dos seus filhos, neto por adopção do próprio imperador, dedica Tácito os capítulos 23-24 do Livro 6, revelando-nos que Druso morreu extinguindo-se numa agonia lenta de nove dias, depois de, pelo desespero da fome a que o obrigavam, ter comido o enchimento do colchão em que dormia no cativeiro. É a desumanidade desse destino que o historiador nos faz olhar antes de mais, provocando no leitor um sobressalto de terror e piedade que o leva a compadecer-se da desgraça de alguém que, nascido na família imperial e por isso naturalmente sob signo auspicioso, acaba encarcerado pelo seu próprio avô, lutando para sobreviver e enlouquecido de fome, nas masmorras subterrâneas do Palatium. A referência explícita ao local do calabouço sugere ao leitor a impassível crueza de Tibério, imune ao poder de qualquer afecto, capaz de manter o neto, anos a fio, nas mais abjectas condições, tão perto do local onde outrora fora um dos possíveis herdeiros do império.

Para que o leitor se compadeça de mais esta vítima de Tibério, Tácito não retoma neste passo nenhuma das informações negativas que dera sobre Druso em 4.60, quando o mostrou colaborando com Sejano para a perdição do irmão mais velho e elencou as razões dessa atitude traiçoeira. Em sábia distribuição do material de que faz a sua história, a Tácito interessa focar aqui apenas a revoltante condição a que, no tempo de Tibério, era possível reduzir um ser humano, para nos mostrar que ninguém, nem mesmo um colaborador de Sejano, nem mesmo um ser violento e traidor dos mais sagrados laços familiares, merece morrer daquela forma.

Todos os crimes de Tibério parecem, assim, nos diferentes actos de que se compõe esta história trágica, concentrar-se num número restrito de espaços aos quais Tácito atribui não um valor descritivo mas um significado simbólico que cabe ao leitor compreender.

São os espaços fechados das prisões onde são lançados seres inocentes e sem defesa, para apodrecerem anos a fio até ao momento da morte, para serem mantidos na maior ignomínia até à execução ou até ao desespero com que buscam o fim. São as ruas e as praças por onde as vítimas da tirania ou da vileza de outros homens são arrastadas para o suplício, e que se fazem deserto à sua passagem. É a cúria para onde tantos e tantos são levados, para serem julgados em processo sumário ou viciado, numa farsa de aplicação da justiça, a cúria que é lugar da infâmia dos senadores capazes de abdicar da honra para manterem a vida, ainda que talvez não por muito tempo, e seja qual for o preço que tenham de pagar por esse adiamento da desgraça. São as casas, lugar da intimidade, dos afectos, da segurança e da vida, devassadas pelos soldados sinistros, espaço onde se afoitam os predadores, seguros de que nada lhes travará o passo ou lhes censurará a delação, as casas donde, sem razão nem aviso, é possível arrancar 
um homem para o executar daí a pouco. Dentro das casas, são os quartos onde os dramas mais íntimos e a solidão mais funda rodeiam o homem e o prendem num laço de que só a morte o pode libertar, forma derradeira de ser humano e de sair da vida com a dignidade ilesa ou enfim recuperada. São as ilhas, espaço limitado de prisão em que os exilados vêem os anos passar, sem esperança na remissão da pena, guardados como bichos por gente sem escrúpulos ou de baixa extracção, à espera do momento em que um deles erga a espada ou em que, lá longe no horizonte, surja o barco que traz as ordens e os algozes de Roma.

E de novo vem à nossa memória o vulto de Semprónio Graco, recortado no cenário de um mar imenso que a certeza da morte torna, a um tempo, calmo e perturbador. É que a beleza dessa imagem faz gritante a interpelação que Tácito deixa aos seus leitores. Aos do seu tempo, porque queria que não se apagasse o exemplo daqueles que tinham sabido conservar intacta a dignidade, e porque entendia que não deviam ficar sem condenação todos os que tinham feito do século I um tempo contínuo de dolorosa e inumana agonia, como era o caso dos imperadores, os seus sequazes e os delatores, ou os que com eles eram coniventes, como os patres.

Mas a nós, os leitores de hoje, que têm a ver connosco os homens e as mulheres que Tácito nos mostra no supremo momento de suas vidas? Que têm eles para nos dizer? Talvez estejam aí para nos deixar uma série de incómodas e intemporais perguntas: Até onde é capaz de ir a violência do ser humano? Até onde tem um homem forças para resistir à força dos que tudo podem? Até onde é capaz de guardar a sua dignidade e de recusar esmagar os outros para se exaltar ou proteger a si mesmo? De que é capaz um ser humano quando acossado pelo medo? Até que ponto o silêncio perante a prepotência e o desviar os olhos da desgraça dos outros não pactuam com essa prepotência e são instrumento dessa desgraça? E talvez seja por isso, porque nos interpela sobre o sentido e os limites da dignidade humana, que não lemos Tácito sem que dentro de nós algo estremeça, no gélido arrepio da sensação de que não é só do século I d.C. que o historiador fala. 